\title{
New Iterative Methods for Solving Nonlinear Equations and Their Basins of Attraction
}

\author{
O.ABABNEH \\ Zarqa university \\ Department of Mathematics \\ JORDAN
}

\begin{abstract}
The purpose of this paper is to propose new modified Newton's method for solving nonlinear equations and free from second derivative. Convergence results show that the order of convergence is four. Several numerical examples are given to illustrate that the new iterative algorithms are effective.In the end, we present the basins of attraction to observe the fractal behavior and dynamical aspects of the proposed algorithms.
\end{abstract}

Key-Words: Nonlinear equations, Newton's method, Basins of Attraction, Order of convergence.

Received: March 15, 2021. Revised: November 10, 2021. Accepted: December 16, 2021. Published: January 3, 2022.

\section{Introduction}

Solving the nonlinear equation is a non-trivial task that has nice applications in various branches of physics and engineering. One of the most important techniques in order to approximate nonlinear equations are iterative methods $[2,3, ?, ?, 20]$. This is an area of research that has grown exponentially over the last few years. Sometimes the applications of the numerical methods to solve non-linear equations depending on the second derivatives are restricted in physics and engineering. In this paper, we consider iterative methods to find a simple root of a nonlinear equation $f(x)=0$, where $\mathrm{f}$ is a scalar function. The classical Newtons method is given by

$$
x_{n+1}=x_{n}-\frac{f\left(x_{n}\right)}{f^{\prime}\left(x_{n}\right)}, \mathrm{n}=0,1,2, \ldots
$$

This is an important and basic method [?], which converges quadratically. To improve the local order of convergence of Newtons method, many third-order methods are developed. A family of third-order methods, called Chebyshev Halley methods [14], is defined as $[15,9]$

$$
x_{n+1}=x_{n}-\left(1+\frac{L_{f}\left(x_{n}\right)}{1-\alpha L_{f}\left(x_{n}\right)}\right) \frac{f\left(x_{n}\right)}{f^{\prime}\left(x_{n}\right)}, \alpha \in R .
$$

where

$$
L_{f}\left(x_{n}\right)=\frac{1}{2} \frac{f^{\prime \prime}\left(x_{n}\right) f\left(x_{n}\right)}{f^{\prime}\left(x_{n}\right)^{2}} .
$$

This family includes the classical Chebyshevs method $(\alpha=0)$, Halleys method $(\alpha=1)$ and Super-Halley $\operatorname{method}(\alpha=2)$. It is clear that to implement (2), one has to evaluate the second derivative of the function. This can create some problems. In order to overcome this drawback, several techniques have been developed [7, 12, 27, 28, 32, 21, 31]. On the other hand, the super-Halley method can be viewed as particular one of the following general form defined by:

$$
\begin{gathered}
x_{n+1}=x_{n}-\left(1+L_{f}\left(x_{n}\right)+\frac{\beta L_{f}\left(x_{n}\right)^{2}}{1-\alpha L_{f}\left(x_{n}\right)}\right) \frac{f\left(x_{n}\right)}{f^{\prime}\left(x_{n}\right)}, \\
\alpha, \beta \in R .
\end{gathered}
$$

This family is known to be third order, but it depends on second derivative, so its use is severely restricted in applications from a practical point of view. Therefore, it is important and interested to develop iterative methods which are free from second derivative and whose order is higher than three if possible. The aim, in the present paper to improves the thirdorder method in (4) to obtain a family of fourth-order method free from second derivative. Moreover, per iteration in these new methods require two evaluations of the function and just one of its first derivative.The remaining part of the paper is organized as follows.

In Section 2 and 3, the Description of the new methods are given. in section 4 , the convergence analysis is given. Furthermore, some examples of the new methods are suggested. In Section 5, the proposed methods are tested on some functions, and the results are compared with other methods. at the end of this work, in section 6 , the basins of attraction are also presented. 


\section{Description of the methods}

In [8], Chun Suggestes new fourth order modifications of Newton's method by using any two existing fourthorder methods to give new fourth-order methods. As an illustrated example, Chun consider the doubleNewton method with fourth-order convergence [43] given by

$$
x_{n+1}=x_{n}-\frac{f\left(x_{n}\right)}{f^{\prime}\left(x_{n}\right)}-\frac{f\left(y_{n}\right)}{f^{\prime}\left(y_{n}\right)},
$$

the fourth-order method given by

$x_{n+1}=x_{n}-\frac{f\left(x_{n}\right)}{f^{\prime}\left(x_{n}\right)}-\left[1+2 \frac{f\left(y_{n}\right)}{f\left(x_{n}\right)}+\frac{f\left(y_{n}\right)^{2}}{f\left(x_{n}\right)^{2}}\right] \frac{f\left(y_{n}\right)}{f^{\prime}\left(x_{n}\right)}$,

and King's fourth-order family of methods [26] given by

$x_{n+1}=x_{n}-\frac{f\left(x_{n}\right)}{f^{\prime}\left(x_{n}\right)}-\frac{f\left(x_{n}\right)+\beta f\left(y_{n}\right)}{f\left(x_{n}\right)+(\beta-2) f\left(y_{n}\right)} \frac{f\left(y_{n}\right)}{f^{\prime}\left(x_{n}\right)}$,

Where $\beta \in R$. Approximately equaling the correction terms of the methods (5) and (6), he obtained an approximation to $f^{\prime}\left(y_{n}\right)$

$$
f^{\prime}\left(y_{n}\right) \approx \frac{f^{\prime}\left(x_{n}\right) f\left(x_{n}\right)^{2}}{f\left(x_{n}\right)^{2}+2 f\left(x_{n}\right) f\left(y_{n}\right)+f\left(y_{n}\right)^{2}}
$$

Approximately equaling the correction terms of the methods (5) and (7), he obtained another approximation to $f^{\prime}\left(y_{n}\right)$

$$
f^{\prime}\left(y_{n}\right) \approx \frac{f^{\prime}\left(x_{n}\right)\left[f\left(x_{n}\right)+(\beta-2) f\left(y_{n}\right)\right]}{f\left(x_{n}\right)+\beta f\left(y_{n}\right)} .
$$

Finally, he applied the respective approximation(8) and (9) to the fifth-order method proposed in [18] given by

$$
x_{n+1}=x_{n}-\frac{f\left(x_{n}\right)}{f^{\prime}\left(x_{n}\right)}-\frac{f^{\prime}\left(y_{n}\right)+3 f^{\prime}\left(x_{n}\right)}{5 f^{\prime}\left(y_{n}\right)-f^{\prime}\left(x_{n}\right)} \frac{f\left(y_{n}\right)}{f^{\prime}\left(x_{n}\right)} .
$$

Per iteration this method requires two evaluations of the function and two evaluations of its firstderivative, Using (8) in (10) to obtain the new method

$$
\begin{gathered}
x_{n+1}=x_{n}-\frac{f\left(x_{n}\right)}{f^{\prime}\left(x_{n}\right)} \\
-\frac{4 f\left(x_{n}\right)^{2}+6 f\left(x_{n}\right) f\left(y_{n}\right)+3 f\left(y_{n}\right)^{2}}{4 f\left(x_{n}\right)^{2}-2 f\left(x_{n}\right) f\left(y_{n}\right)-f\left(y_{n}\right)^{2}} \frac{f\left(y_{n}\right)}{f^{\prime}\left(x_{n}\right)} .
\end{gathered}
$$

Using (9) in (10), to obtain the new family of methods

$$
\begin{gathered}
x_{n+1}=x_{n}-\frac{f\left(x_{n}\right)}{f^{\prime}\left(x_{n}\right)} \\
-\frac{2 f\left(x_{n}\right)+(2 \beta-1) f\left(y_{n}\right)}{2 f\left(x_{n}\right)+(2 \beta-5) f\left(y_{n}\right)} \frac{f\left(y_{n}\right)}{f^{\prime}\left(x_{n}\right)},
\end{gathered}
$$

where $\beta \in R$. fined by

Noor [36] proposed new fourth order method de-

$$
\begin{aligned}
x_{n+1}=y_{n} & -\frac{f\left(y_{n}\right)}{f^{\prime}\left(x_{n}\right)}-\left(\frac{f\left(y_{n}\right)}{f^{\prime}\left(x_{n}\right)}\right)\left(1-\frac{f^{\prime}\left(y_{n}\right)}{f^{\prime}\left(x_{n}\right)}\right) \\
& -\frac{1}{2}\left(\frac{f\left(y_{n}\right)}{f^{\prime}\left(x_{n}\right)}\right)^{2} \frac{f^{\prime \prime}\left(y_{n}\right)}{f^{\prime}\left(x_{n}\right)},
\end{aligned}
$$

where $y_{n}=x_{n}-f\left(x_{n}\right) / f^{\prime}\left(x_{n}\right)$.

It is clear that to implement (13), one has to evaluate the second derivative of the function. This can create some problems. In [34], a second-derivative-free method is obtained through approximating the second derivative $f^{\prime \prime}\left(y_{n}\right)$ in (14) by

$$
f^{\prime \prime}\left(y_{n}\right) \cong \frac{f^{\prime}\left(y_{n}\right)-f^{\prime}\left(x_{n}\right)}{y_{n}-x_{n}} .
$$

Noor and Khan [35] have used the same approximation of the second derivative (14) in (13) to suggest the following Iterative methods

$$
\begin{gathered}
x_{n+1}=y_{n}-\frac{2 f\left(y_{n}\right)}{f^{\prime}\left(x_{n}\right)}+\frac{f\left(y_{n}\right) f^{\prime}\left(y_{n}\right)}{f^{\prime 2}\left(x_{n}\right)} \\
+\frac{f^{\prime}\left(y_{n}\right)-f^{\prime}\left(x_{n}\right)}{2 f\left(x_{n}\right)}\left(\frac{f\left(y_{n}\right)}{f^{\prime}\left(x_{n}\right)}\right)^{2} .
\end{gathered}
$$

In [1], we rederive the method in (15) to obtain a family of fourth-order method free from second derivative. Moreover, per iteration in these new methods require two evaluations of the function and just one of its first derivative as follow:

Combining (8) and (15), we get the new iterative method

$$
\begin{aligned}
& x_{n+1}=y_{n}-\left(\frac{2 f\left(y_{n}\right)}{f^{\prime}\left(x_{n}\right)}\right)+\left(\frac{f\left(x_{n}\right)^{2} f\left(y_{n}\right)}{f^{\prime}\left(x_{n}\right)\left(f\left(x_{n}\right)+f\left(y_{n}\right)\right)^{2}}\right) \\
& +\left(-\frac{f\left(y_{n}\right) f^{\prime}\left(x_{n}\right)\left(2 f\left(x_{n}\right)+f\left(y_{n}\right)\right)}{2 f\left(x_{n}\right)\left(f\left(x_{n}\right)+f\left(y_{n}\right)\right)^{2}}\right)\left(\frac{f\left(y_{n}\right)}{f^{\prime}\left(x_{n}\right)}\right)^{2} \cdot(16)
\end{aligned}
$$

Using (9) in (15), we get a new family of iterative method

$x_{n+1}=y_{n}-\left(\frac{2 f\left(y_{n}\right)}{f^{\prime}\left(x_{n}\right)}\right)+\left(\frac{f\left(y_{n}\right)\left(f\left(x_{n}\right)+f\left(y_{n}\right)(\beta-2)\right)}{f^{\prime}\left(x_{n}\right)\left(f\left(x_{n}\right)+\beta f\left(y_{n}\right)\right)}\right)$ 


$$
+\left(\frac{-f^{\prime}(x) f(y)}{f(x)(f(x)+\beta f(y))}\right)\left(\frac{f\left(y_{n}\right)}{f^{\prime}\left(x_{n}\right)}\right)^{2} .
$$

Numerical results show that the number of iterations of the new method are always less than that of the classical Newton's method and the method in (15).

\subsection{New approximation of the second derivative and derive new methods}

let us consider the third-order methods defined by

$$
x_{n+1}=x_{n}-\frac{f\left(x_{n}\right)^{2}}{f^{\prime}\left(x_{n}\right)\left(f\left(x_{n}\right)-f\left(y_{n}\right)\right)},
$$

where

$$
y_{n}=x_{n}-\frac{f\left(x_{n}\right)}{f^{\prime}\left(x_{n}\right)}
$$

which is third order method often called NewtonSteffensen method and

$$
x_{n+1}=x_{n}-\frac{f\left(x_{n}\right)}{f^{\prime}\left(x_{n}\right)}-\frac{f\left(x_{n}\right)^{2} f^{\prime \prime}\left(x_{n}\right)}{2 f^{\prime}\left(x_{n}\right)^{3}},
$$

which is known as the Householder iterative method [19]. We approximately equate the correcting terms of both methods to obtain the following approximate expression:

$$
\frac{f\left(x_{n}\right)^{2}}{f^{\prime}\left(x_{n}\right)\left(f\left(x_{n}\right)-f\left(y_{n}\right)\right)} \approx \frac{f\left(x_{n}\right)}{f^{\prime}\left(x_{n}\right)}+\frac{f\left(x_{n}\right)^{2} f^{\prime \prime}\left(x_{n}\right)}{2 f^{\prime}\left(x_{n}\right)^{3}}
$$

this gives a new approximation

$$
f\left(x_{n}\right)^{\prime \prime} \approx \frac{2 f^{\prime 2}\left(x_{n}\right) f\left(y_{n}\right)}{f\left(x_{n}\right)\left(f\left(x_{n}\right)-f\left(y_{n}\right)\right)} .
$$

A family of third-order methods, called Chebyshev Halley methods [14], is defined as [15, 9]

$$
x_{n+1}=x_{n}-\left(1+\frac{L_{f}\left(x_{n}\right)}{1-\alpha L_{f}\left(x_{n}\right)}\right) \frac{f\left(x_{n}\right)}{f^{\prime}\left(x_{n}\right)}, \alpha \in R .
$$

where

$$
L_{f}\left(x_{n}\right)=\frac{1}{2} \frac{f^{\prime \prime}\left(x_{n}\right) f\left(x_{n}\right)}{f^{\prime}\left(x_{n}\right)^{2}} .
$$

This family includes the classical Chebyshevs method $(\alpha=0)$, Halleys method $(\alpha=1)$ and SuperHalley method $(\alpha=2)$. It is clear that to implement 23 , one has to evaluate the second derivative of the function. On the other hand, the super-Halley method can be viewed as particular one of the following general form defined by:

$$
\begin{gathered}
x_{n+1}=x_{n}-\left(1+L_{f}\left(x_{n}\right)+\frac{\beta L_{f}\left(x_{n}\right)^{2}}{1-\alpha L_{f}\left(x_{n}\right)}\right) \frac{f\left(x_{n}\right)}{f^{\prime}\left(x_{n}\right)} \\
, \alpha, \beta \in R .
\end{gathered}
$$

This family is known to be third order, but it depends on second derivative, so that its use is severely restricted in applications from a practical point of view. Therefore, it is important and interesting to develop iterative methods which are free from second derivative and whose order is higher than three if possible, this is main motivation of this paper.

Using 22 in 24 we obtain

$$
L_{f}\left(x_{n}\right)=\frac{1}{2} \frac{f^{\prime \prime}\left(x_{n}\right) f\left(x_{n}\right)}{f^{\prime}\left(x_{n}\right)^{2}} \approx \frac{f\left(y_{n}\right)}{f\left(x_{n}\right)-f\left(y_{n}\right)},
$$

using 26 in 25 we obtain a new family of the secondderivative -free method defined as following

$$
\begin{gathered}
x_{n+1}=y_{n}-\left(1+\frac{\beta f\left(y_{n}\right)}{f\left(x_{n}\right)-f\left(y_{n}\right)(1+\alpha)}\right) \\
\frac{f\left(x_{n}\right) f\left(y_{n}\right)}{f^{\prime}\left(x_{n}\right)\left(f\left(x_{n}\right)-f\left(y_{n}\right)\right)},
\end{gathered}
$$

where

$$
y_{n}=x_{n}-\frac{f\left(x_{n}\right)}{f^{\prime}\left(x_{n}\right)} .
$$

For the methods defined by 27 , we have the following convergence result.

\section{Convergence analysis}

In order to establish the order of convergence and other properties of the new methods, we state some of the important definitions . A sequence $x_{0}, x_{1}, x_{2}, \ldots, x_{n}, \ldots$ of approximations to the zero $\alpha$, generated by an iterative function $\phi$, presumably converges to $\alpha$. More precisely, if there holds $\lim _{n \rightarrow \infty} x_{n}=$ $\alpha$, we say that the sequence of approximations $\left\{x_{n}\right\}$ is convergent. Convergence conditions depend on the form of the iteration function, its properties and the chosen initial approximation .

Definition 1 [40] Let $\phi: R \rightarrow R$ be an iterative function which defines the iterative process $X_{n+1}=$ $\phi\left(x_{n}\right)$. If there exists a real number $p$ and a nonzero constant $\lambda$ such that $\lim _{n \rightarrow \infty} \frac{\left|\phi\left(x_{n}\right)-\alpha\right|}{\left|x_{n}-\alpha\right|^{p}}=\lambda$, then $p$ is called the order of convergence and $\lambda$ is the asymptotic error constant. If $p=2$ or 3 , the convergence is said to be quadratic or cubic, respectively [39, 40]. 
Let $e_{n}=x_{n}-\alpha$ be the error of the approximation in the $n^{\text {th }}$ iterative step. Then $e_{n+1}=x_{n+1}-\alpha=$ $\phi\left(x_{n}\right)-\alpha$. Hence, $\lim _{n \rightarrow \infty} \frac{\left|\phi\left(x_{n}\right)-\alpha\right|}{\left|x_{n}-\alpha\right|^{p}}=\lim _{n \rightarrow \infty} \frac{\left|x_{n+1}-\alpha\right|}{\left|x_{n}-\alpha\right|^{P}}=$ $\lim _{n \rightarrow \infty} \frac{\left|e_{n+1}\right|}{\left|e_{n}\right|^{P}}=\lambda$

Definition 2 : [39] Let $r$ be the number of function evaluations of the method. The efficiency of the method is measured by the concept of Efficiency Index and defined as $\sqrt[r]{p}=p^{1 / r}$, where $p$ is the order of convergence.

Theorem 3 Let $\alpha \in I$ be a simple zero of sufficiently differentiable function $f: I \rightarrow R$ for an open interval I. If $x_{o}$ is sufficiently close to $\alpha$, where $e_{n}=x_{n}-\alpha$ and $c_{k}=f^{(k)}(\alpha) / k$ !. Then the family defined by 27 is of fourth-order convergence if $\beta=1$ and for any $\alpha \in R$.

Proof Using Taylor expansion of $f\left(x_{n}\right)$ about $\alpha$ and taking into account that $f^{\prime}(\alpha) \neq 0$ we have

$f\left(x_{n}\right)=f^{\prime}(\alpha)\left[e_{n}+c_{2} e_{n}^{2}+c_{3} e_{n}^{3}+c_{4} e_{n}^{4}+O\left(e_{n}^{5}\right)\right]$.

Furthermore, we have

$f^{\prime}\left(x_{n}\right)=f^{\prime}(\alpha)\left[1+2 c_{2} e_{n}+3 c_{3} e_{n}^{2}+4 c_{4} e_{n}^{3}+O\left(e_{n}^{4}\right)\right]$.

and

$$
\begin{gathered}
\frac{f\left(x_{n}\right)}{f^{\prime}\left(x_{n}\right)}=e_{n}-c_{2} e_{n}^{2}+2\left(c_{2}^{2}-c_{3}\right) e_{n}^{3}+\left(7 c_{2} c_{3}-4 c_{2}^{3}-3 c_{4}\right) e_{n}^{4} \\
+O\left(e_{n}^{5}\right) .
\end{gathered}
$$

Substituting 31 in 28 yields

$$
\begin{gathered}
y_{n}-\alpha=c_{2} e_{n}^{2}-2\left(c_{2}^{2}-c_{3}\right) e_{n}^{3} \\
-\left(7 c_{2} c_{3}-4 c_{2}^{3}-3 c_{4}\right) e_{n}^{4}+O\left(e_{n}^{5}\right) .
\end{gathered}
$$

Expanding $f\left(y_{n}\right)$ about $\alpha$ and using 32, we have

$$
\begin{gathered}
f\left(y_{n}\right)=f^{\prime}(\alpha)\left[c_{2} e_{n}^{2}-2\left(c_{2}^{2}-c_{3}\right) e_{n}^{3}\right. \\
-\left(7 c_{2} c_{3}-4 c_{2}^{3}-3 c_{4}\right) e_{n}^{4}+O\left(e_{n}^{5}\right) .
\end{gathered}
$$

Using Eqs. 29-33 in method 27 we have the following error equation:

$$
\begin{gathered}
e_{n+1}=(1-\beta) c_{2}^{2} e^{3} \\
-c_{2}\left(3 c_{2}^{2}-6 \beta c_{2}^{2}+\beta \alpha c_{2}^{2}-3 c_{3}+4 \beta c_{3}\right) e^{4}+O\left(e_{n}^{5}\right) .
\end{gathered}
$$

Therefore, the iteration function defined by (27) is of order at least four for $\beta$ making the coefficient of $e^{3}$ in (34) zero. Thus, we need $\beta=1$, this means that the method defined by (27) is fourth order. This completes the proof of the theorem.

If we consider the definition of efficiency index [13] as $p^{\frac{1}{w}}$, where $p$ is the order of the method and $w$ is the number of function evaluations per iteration required by the method, then the new family method (27) has the efficiency index equal to $\sqrt[3]{4} \simeq 1.5874$.

\subsection{Some examples}

As an example of family (27), we choose some different values of $\alpha$, to get some new fourth order methods as follow:

for $\alpha=1$, we obtain a new fourth order method

$$
\left\{\begin{array}{l}
y_{n}=x_{n}-\frac{f\left(x_{n}\right)}{f^{\prime}\left(x_{n}\right)}, \\
x_{n+1}=y_{n}-\frac{f\left(x_{n}\right)}{f\left(x_{n}\right)-2 f\left(y_{n}\right)} \frac{f\left(y_{n}\right)}{f^{\prime}\left(x_{n}\right)}
\end{array}\right.
$$

for $\alpha=0$, we obtain a new fourth order method

$$
\left\{\begin{array}{l}
y_{n}=x_{n}-\frac{f\left(x_{n}\right)}{f^{\prime}\left(x_{n}\right)}, \\
x_{n+1}=y_{n}-\frac{f^{2}\left(x_{n}\right)}{\left(f\left(x_{n}\right)-f\left(y_{n}\right)\right)^{2}} \frac{f\left(y_{n}\right)}{f^{\prime}\left(x_{n}\right)},
\end{array}\right.
$$

for $\alpha=-1$, we obtain a new fourth order method

$$
\left\{\begin{array}{l}
y_{n}=x_{n}-\frac{f\left(x_{n}\right)}{f^{\prime}\left(x_{n}\right)}, \\
x_{n+1}=y_{n}-\frac{f\left(x_{n}\right)+f\left(y_{n}\right)}{f\left(x_{n}\right)-f\left(y_{n}\right)} \frac{f\left(y_{n}\right)}{f^{\prime}\left(x_{n}\right)} .
\end{array}\right.
$$

\section{Numerical Results}

In this section, we present the results of some numerical tests to compare the efficiencies of the new methods . Numerical computations reported here have been carried out in a MTHEMATICA environment . The stopping criterion has been taken as $\left|x_{n+1}-x_{n}\right|<\varepsilon$, We used the fixed stopping criterion $\varepsilon=10^{-14}$. In Table 1 , the test functions has been used. The test results in Table 2, Show that for most of the functions we tested the new methods proposed in this paper have better performance than the other existing methods.

In some cases, we consider the present methods (OA1), (OA2) and (OA3) works better than (TM) method. Note that we used NC in Table 2 to mean that the method does not converge to the root. As a conclusion, we can infer that the new methods has better performance in accordance with the theoretical analysis of the order. However, it should be noted that for 
Table 1: Test function

\begin{tabular}{cc}
$x$ & $\operatorname{Root}(\alpha)$ \\
\hline$f_{1}(x)=x^{3}+4 x^{2}-10$ & $\alpha=1.365230013414096$ \\
$f_{2}(x)=\sin ^{2} x-x^{2}+1$ & $\alpha=1.404491648215341$ \\
$f_{3}(x)=x^{2}-e^{x}-3 x+2$ & $\alpha=0.257530285439860$ \\
$f_{4}(x)=\cos x-x$ & $\alpha=0.739085133215160$ \\
$f_{5}(x)=(x-1)^{3}-2$ & $\alpha=2.259921049894873$ \\
$f_{6}(x)=x e^{x^{2}}-\sin ^{2} x+3 \cos x+5$ & $\alpha=-1.207647827130919$ \\
$f_{7}(x)=(x+2) e^{x}-1$ & $\alpha=-0.442854401002388$ \\
$f_{8}(x)=e^{\left(x^{2}+7 x-30\right)}-1$ & $\alpha=3.000000000000000$
\end{tabular}

per iteration the new methods require just two functions evaluation and one of its first derivative. Thus, the present methods can be of practical interest.

Table 2: Comparison of various iterative schemes and the new methods, the number of iterations to approximate the zero. Newton method (NM), Chebysheves method (2)(CM), a modified super Halley fourth order $(\mathrm{MH})$ optimal method [9], Traub-Ostrowski method (TM)[38] and the new methods in (18-20) (OA1),(OA2) and (OA3) respectively.

\begin{tabular}{cccccccc}
\hline$f(x)$ & NM & CM & MH & TM & OA1 & OA2 & OA3 \\
\hline$f_{1}, x_{0}=-0.3$ & 53 & 8 & 75 & 60 & 31 & 11 & 7 \\
$f_{2}, x_{0}=2.0$ & 5 & 4 & 3 & 3 & 3 & 3 & 3 \\
$f_{2}, x_{0}=1.0$ & 6 & 5 & 3 & 3 & 3 & 3 & 4 \\
$f_{3}, x_{0}=1.0$ & 4 & 3 & 3 & 2 & 2 & 2 & 2 \\
$f_{3}, x_{0}=2.0$ & 5 & 3 & 4 & 3 & 3 & 3 & 3 \\
$f_{4}, x_{0}=1.0$ & 4 & 3 & 3 & 2 & 2 & 2 & 2 \\
$f_{4}, x_{0}=1.7$ & 4 & 4 & 3 & 3 & 3 & 3 & 3 \\
$f_{5}, x_{0}=-0.3$ & 9 & 30 & 5 & 10 & 10 & 3 & 5 \\
$f_{5}, x_{0}=0.0$ & $N C$ & 5 & $N C$ & 9 & 9 & 6 & 7 \\
$f_{6}, x_{0}=-1.0$ & 5 & 4 & 3 & 3 & 3 & 3 & 3 \\
$f_{6}, x_{0}=-3.0$ & 14 & 9 & 8 & 6 & 6 & 7 & 8 \\
$f_{7}, x_{0}=2.0$ & 8 & 6 & 5 & 4 & 4 & 4 & 5 \\
$f_{7}, x_{0}=-0.5$ & 4 & 3 & 3 & 2 & 2 & 2 & 2 \\
$f_{8}, x_{0}=3.5$ & 12 & 8 & 7 & 5 & 5 & 6 & 7 \\
$f_{8}, x_{0}=1.0$ & 19 & 13 & 11 & 8 & 8 & 10 & 11 \\
\hline
\end{tabular}

\section{Basins of Attraction}

The basin of attraction is a region of the phase space where iterations are defined. such that any point in that region will eventually be iterated into the attractor. It can be used to compare the efficiency of various algorithms. See, for example[4, 5]

The aim of this section is to represent the basins for the proposed algorithms by using graphical tools as Mathematica. The colors of basins of attraction vary depending on the number of iterations necessary to obtain the approximate solution of polynomials with given accuracy. the detailed study of basins of attraction, its theoretical background, and applications are discussed in $[16,17,22,23]$.
We assign a color to the attraction of a root. We make the same color lighter or darker depending on the number of iterations needed to reach the root with the fixed precision required.

we will apply the iterative methods proposed in the previous section to get the complex roots of functions.

$f(z)=z^{3}-1$ and $f(x)=\exp \left(\frac{\sin z}{100}\right)\left(z^{3}-1\right)$.

We start by taking a rectangle $D \subset C$ and we apply the iterative methods. starting in $z_{0} \in D$. In practice, we take a grid of $1024 \times 1024$ points in $\mathrm{D}$ and we use these points as $z_{0}$.

All the figures have been generated using the computer program Mathematica 10.0 by taking a tolerance $\varepsilon=10^{-8}$ and a maximum of 40 iterations. We denote the three roots as $\zeta=e^{2 k \pi i / 3}, k=0,1,2$ Then, we take $z_{0}$ in the corresponding rectangle and we iterate $z_{n+1}$ up to $\left|S z_{n}-\zeta_{k}\right|<\varepsilon$ for $k=0,1,2$

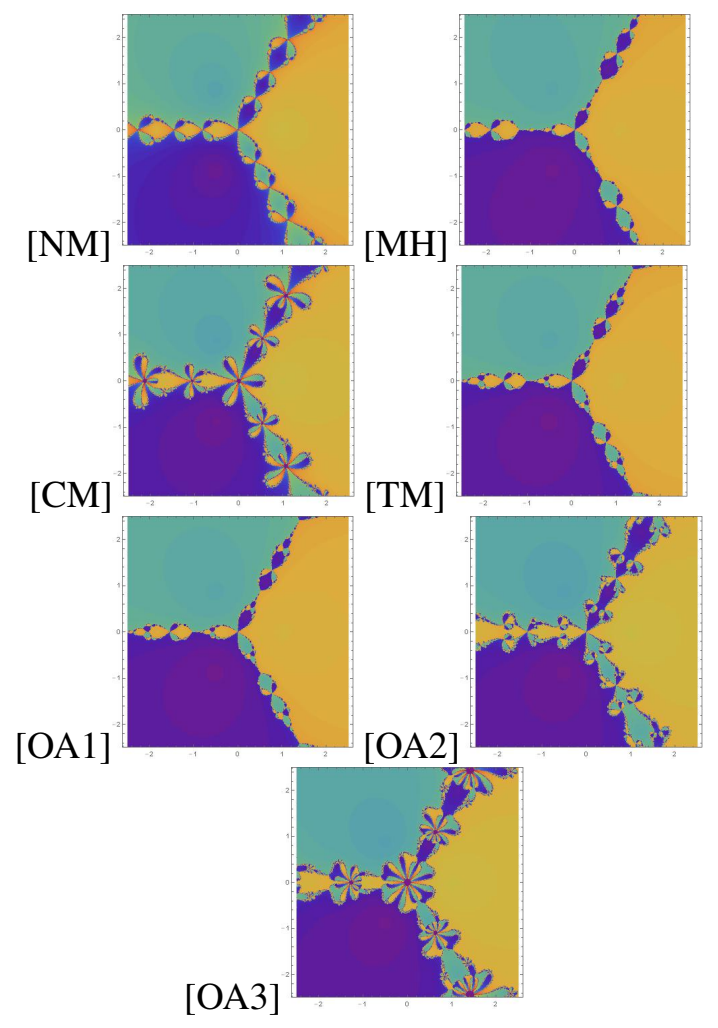

Figure 1: Dynamical planes on $f(z)=z^{3}-1$

In the first example, we have apply all the proposed algorithms to obtain the simple roots of the cubic complex polynomial. The results of the basin of attractions are presented in Figure 1. For each root of the considered polynomial, there exists a unique color on the corresponding basins of attraction, that can be easily seen from Figure 1. In the next example, which has three roots also. The basins of attraction are presented in Figure 2. three unique colors corresponding to the distinct roots can be seen in Figure 2. 


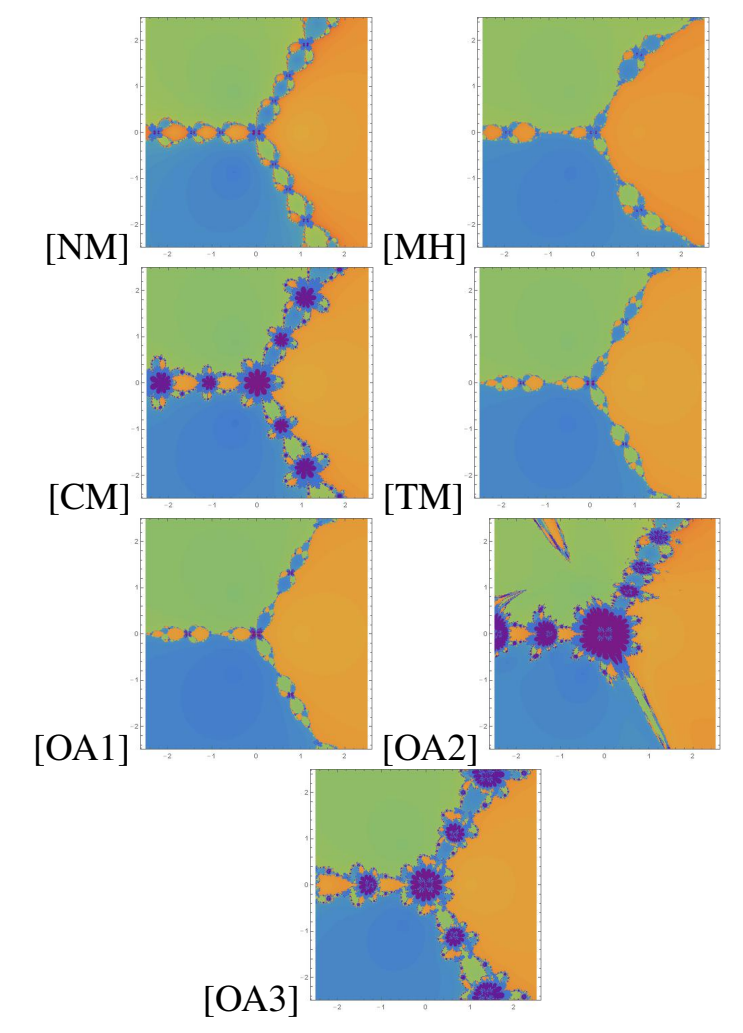

Figure 2: Dynamical planes on $f(x)=$ $\exp \left(\frac{\sin z}{100}\right)\left(z^{3}-1\right)$

\section{Conclusion}

In this paper new optimal fourth order root-finding algorithms for solving nonlinear equations have been proposed.

Table 2 show the best performance of the new methods in terms of number of iterations, and order of convergence as compared to other well-known existing methods. We have also presented the basins of attraction by using some complex functions through newly developed methods which describe the fractal behavior and dynamical aspects of the proposed methods.

\section{References:}

[1] O.Y. Ababneh, New Fourth Order Iterative Methods Second Derivative Free, Journal of Applied Mathematics and Physics. 4 (2016), 519523

[2] I.K. Argyros, A.A. AMagre Contemporary Study of Iterative Methods; Academic Press: Cambridge, MA, USA, (2018).

[3] I.K. Argyros, A.A. Magre Iterative Methods and Their Dynamics with Applications: A Contem- porary Study; CRC Press: Boca Raton, FL, USA, (2017).

[4] C. Chun, B. Neta, Comparative study of methods of various orders for finding simple roots of nonlinear equations. J. Appl. Anal. Comput. 9 (2019),400427.

[5] C. Chun, B.Neta, Comparative study of methods of various orders for finding repeated roots of nonlinear equations. J. Comput. Appl. Math. 340 (2018), 1142.

[6] C. Chun, Y. Ham, Some second-derivative-free variants of super-Halley method with fourthorder convergence, Appl. Math. Compute. 195 (2008), 537-541.

[7] C. Chun, Some third-order families of iterative methods for solving non-linear equations, Appl. Math. Comput. 188(2007), 924-933.

[8] C. Chun, Y. Ham, Some fourth-order modifications of Newtons method, Appl. Math. Comput. 197 (2008), 654-658.

[9] D. Chen, I.K. Argyros, Q.S. Qian, A local convergence theorem for the Super-Halley method in a Banach space, Appl. Math. Lett. 7(5)(1994).

[10] C. Chun, Some third-order families of iterative methods for solving non linear equations, Appl. Math. Comput. 188 (2007), 924-933.

[11] J. A. Ezquerro, M. A. Hern andez, A uniparametric Halley-type iteration with free second derivative, Int. J. Pure Appl. Math. 6 (2003), 103-114.

[12] J. A. Ezquerro, M. A. Hernandez, A uniparametric Halley-type iteration with free second derivative, Int. J. Pure Appl. Math. 69 (2003), 103-114.

[13] W. Gautschi, Numerical Analysis: An Introduction, Birkhauser, (1997).

[14] J.M. Gutierrez, M.A. Hernandez, A family of CLebyshevHalley type methods in Banach spaces, Bull. Austral. Math. Soc. 55 (1997), 113130.

[15] J.M. Gutierrez, M.A. Hermandez, An acceleration of Newton method: Super-Halley method, Appl. Math. Comput. 117 (2001), 223-239

[16] K. Gdawiec, Fractal patterns from the dynamics of combined polynomial root finding methods, Nonlinear Dynamics, 90 (2017), 24572479, . 
[17] K. Gdawiec, W. Kotarski, and A. Lisowska, Visual analysis of the Newtons method with fractional order derivatives, Symmetry, 11 (2019).

[18] Y. Ham, C. Chun, A fifth-order iterative method for solving nonlinear equation, Appl. Math. Comput. 194 (2007), 287290

A.S. Householder, The Numerical Treatment of a Single Nonlinear Equation, McGraw-Hill, New York, (1970).

[19] A.S. Householder, The Numerical Treatment of a Single Nonlinear Equation, McGraw-Hill, New York, (1970).

[20] Ioannis K. Argyros, Santhosh George, Extended And Unified Local Convergence For NewtonKantorovich Method Under w? Conditions With Applications, WSEAS Transactions on Mathematics, 16(2017), 248-256.

[21] Jain, Pankaj and Bahadur Chand, Prem. Derivative free iterative methods with memory having higher R-order of convergence. International Journal of Nonlinear Sciences and Numerical Simulation, 21 (2020), 641-648. https://doi.org/10.1515/ijnsns-2019-0174

[22] B. Kalantari, E. H. Lee, Newton-Ellipsoid polynomiography, Journal of Mathematics and the Arts, 13 (2019), 336-352.

[23] S. M. Kang, A. Naseem, W. Nazeer, M. Munir, and C. Y. Jung, Polynomiography of some iterative methods, International Journal of Mathematical Analysis, 11 (2017), 133-149.

[24] Y. C. Kwun, Z. Majeed, A. Naseem, W. Nazeer, and S. M. Kang, New iterative methods using variational iteration technique and their dynamical behavior, International Journal of Pure and Applied Mathematics, 116 (2017), 1093-1113.

[25] D. Kinkaid, W. Chenney, Numerical analysis: mathematics of scientific computing, $\operatorname{AMS}(2009)$.

[26] R. King, A local convergence theorem for the Super-Halley method in a Banach space, SIAM J. Numer. Anal. 10 (5) (1973), 876879.

[27] J.S. Kou, Y.T. Li, X.H. Wang, A uniparametric Chebyshev-type method free from econd derivatives, Appl. Math. Comput. 179 (2006), 296300.

[28] J.S. Kou, Y.T. Li, X.H. Wang, Modified Halleys method free from second derivative, Appl. Math. Comput. 183 (2006), 704-708.
[29] J.S. Kou, Y.T. Li, X.H. Wang, A uniparametric Chebyshev-type method free from second derivatives, Appl. Math. Comput. 179 (2006), 296-300.

[30] J.S. Kou, Y.T. Li, X.H. Wang, Modified Halley s method free from second derivative, Appl. Math. Comput. 183 (2006), 704-708.

[31] S. Li, Fourth-order iterative method without calculating the higher derivatives for nonlinear equation. Journal of Algorithms Computational Technology.(2019) https://doi.org/10.1177/1748302619887686

[32] B. Neta, A New Derivative-Free Method to Solve Nonlinear Equations. Mathematics, 9 (2021). https://doi.org/ 10.3390/math9060583

[33] M.A. Noor, Some iterative methods for solving nonlinear equations using homotopy perturbation method, Int. J. Comp. Math. 87 (2010), 141149.

[34] M.A. Noor, V. Gupta, Modified Householder iterative method free from second derivatives for nonlinear equations, Appl. Math. Comput. 190 (2007), 1701-1706.

[35] M.A. Noor, W.A. Khan, New iterative methods for solving nonlinear equation by using homotopy perturbation method, Appl. Math. Comput. 219 (2012), 3565-3574.

[36] M.A. Noor, Some iterative methods for solving nonlinear equations using homotopy perturbation method, Int. J. Comp. Math. 87 (2010), 141149.

[37] Ourida Ourahmoun , Newton Raphson method used to model organic solar cells under Matlab software, WSEAS Transactions on Circuits and Systems, 19(2020),181-185

[38] A.M. Ostrowski, Solution of Equations in Eucilidean and Banach Space, third ed., Academic Press, New York, (1973).

[39] A.M Ostrowski, Solutions of Equations and System of Equations, Academic Press, New York, (1960).

[40] M. S. Petkovic, B. Neta, L.D. Petkovic and J. Dzunic, Multipoint Methods for Solving Nonlinear Equations, (2012).

[41] J.R. Sharma, A composite third order NewtonSteffensen method for solving nonlinear equations, App. Math. Comput. 169 (2005), 242-246. 
[42] F.Soleymani, A Novel and Precise Sixth-Order Method for Solving Nonlinear Equations, International Journal of Mathematical Models and Methods in Applied Sciences, 5(2011), 730737.

[43] J.F. Traub, Iterative Methods for the Solution of Equations, New York, (1977).

\section{Creative Commons Attribution License 4.0 (Attribution 4.0 International, CC BY 4.0)}

This article is published under the terms of the Creative Commons Attribution License 4.0

https://creativecommons.org/licenses/by/4.0/deed.en_US 